\title{
Effect of different levels of citric acid on quality and storage stability of sugar and jaggery based papaya (Carica papaya $L$.) fruit bar
}

\author{
Ankit Singh*, Yogendra Singh, Lalit Kumar, Shalini and Ravi Kumar \\ Department of Agricultural Engineering and Food Technology SardarVallabhbhai Patel University of Agriculture \\ \& Technology Modipuram, Meerut - 250110 (U.P.), INDIA \\ *Corresponding Author Email. mailankitsingh@yahoo.com
}

Received: February 10, 2016; Revised received: April 27, 2016; Accepted: June 7, 2016

\begin{abstract}
A study was undertaken to evaluate the effect of different level of citric acid and packaging material on physico chemical quality, sensory quality and shelf life of developed papaya fruit bar. The study revealed that the moisture content (19.06\% to $16.95 \%$ in PET jars $-19.06 \%$ to $17.06 \%$ in glass jars), TSS (64.17 to 69.30 Brix in PET jars and 64.17 to 69.46 Brix in glass jars), Vitamin- $C$ (55.30 to $45.80 \mathrm{mg} / 100 \mathrm{mg}$ in PET jars and 55.30 to 46.75 $\mathrm{mg} / 100 \mathrm{mg}$ in glass jars) and total plate count decreased with increasing the level of citric acid from 0.5 to $1.0 \%$ after 90 days of storage in. During storage there was a reduction in moisture content, $\mathrm{pH}$ and vitamin-C, where as TSS (total soluble solids), optical density and total plate count increased during storage. No microbial detection in developed fresh fruit bar was found. The organoleptic score of the bar samples in glass jars at $0.75 \%$ citric acid level was found to be higher followed by samples packed in PET jars and the developed fruit bar was well acceptable even after 90 days of storage. The result indicated that sugar ${ }_{50}+$ jaggery $_{50}$ at 0.75 percent citric acid level gave better prod-

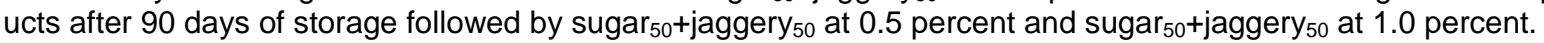

Keywords: Fruit bar, Citric acid, Physicochemical properties, Sensory, Packaging material

\section{INTRODUCTION}

India is the second largest producer of fruits and vegetables. However, about 25 to $30 \%$ produce are wasted due to inadequate facilities of processing, preservation, storage, handling and transportation. The edible portion of papaya is composed mostly of water $(89.6 \%)$ and carbohydrate $(9.5 \%)$ which together makes up $99.10 \%$ of the fruits. Also, papaya fruits contain 6.5 to $13{ }^{0}$ Brix of TSS in the Pusa varieties (Ram, 1982) and $9.8{ }^{0}$ Brix in Loorg honey dew (Singh and Sirohi, 1977). Several changes occur within the papaya during its development. Presently, only the changes in sugar content and papain concentration have been reported in the literature. Ripe fruits contain about 7-9 percent sugar and are valued as breakfast fruit usually with added sugar and lime juice. Preserves of various kinds and marmalades are made from papaya. The fruit is also used for making puree. The important papaya growing states are Andhra Pradesh, Tamil Nadu, Assam, Bihar, Maharashtra and Uttar Pradesh. The papaya fruits are rich source of vitamins, particularly ascorbic acid and $\beta$-carotene. Fruit bars from mango, papaya, pineapple, guava, jamunand banana individually or in combination with different fruits (Mathur et al., 1972, and Doreyappa Gowda et al., 1995). Fruit leather or bar is a ready to eat, semi-moist food with soft gel like texture obtained by dehydration of fruit purees into leathery sheets. These products are gener- ally remaining shelf stable and can be stored safely for longer time at room temperature in PET jar, glass jar or in any type of flexible laminate pouches. In addition, it contains sufficient dissolved solutes to decreases water. Fruit leathers are often considered as a health food and health food marketing images such as "pure," "sun-dried," or "rich in vitamins" are used to describe them (Vatthanakul et al., 2010). Present investigation highlights the storage behaviour of sugar and jaggery based papaya bar with different levels $(0.5 \%, 0.75 \%$ and $1.0 \%)$ of citric acid packed in different packaging materials and kept at room temperature over a period of three months.

\section{MATERIALS AND METHODS}

Preparation of papaya bar: Papaya bar was prepared from evenly ripened fruit of pusa nanha variety procured in bulk from local market. Papaya were washed to potable water and remove dust, dirty particles and some bacteria's. Peeling was done manually. Pulping of papaya was done in Electric Juicer mixer. The papaya fruit pulp $(1.0 \mathrm{~kg})$ was mixed with $225 \mathrm{~g}$ of sugar and $225 \mathrm{~g}$ of jaggery, $7.25 \mathrm{~g}$ of citric acid for the preparation of papaya fruit bar with citric acid level of $0.5 \%$ after preparing papaya bar with citric acid level of $0.5 \%$ the same process is again done for the preparation of papaya bar with citric acid level of 0.75 and $1.0 \%$. The mixture was heated with continous stirring for 5 minutes after cooking $2 \mathrm{ml}$ mixed fruit flavour is 
added in the blend. This blend was spread in the form of thin layer on a tray smeared with mustard oil and dried in the hot air oven at $45{ }^{\circ} \mathrm{C}$. The dried layer was cut into rectangular bar pieces $(3.5 \times 3.5 \times 0.5 \mathrm{~cm})$ and packed individually in PET jars and glass jars and stored at room temperature for further study. Flow chart for the preparation of papaya fruit bar is given in flow diagram (Fig. 1).

\section{Physicochemical properties of papaya bar}

Moisture content (MC): $10 \mathrm{~g}$ of papaya bar were weighed in flat bottom dried tarred dish. The dish and its content were placed in hot air oven (Instron, IN-301 Model, India) which was thermo statistically controlled at $150 \pm 100 \mathrm{C}$ and heated until successive weighing showed no further weight loss. At the end, the dish was removed from the oven and placed in desiccators and allowed to cool and then again weighed. The following method was used for estimation of moisture content of fruit bar samples.

Fig. 1. Flow chart for the preparation of papaya bar.

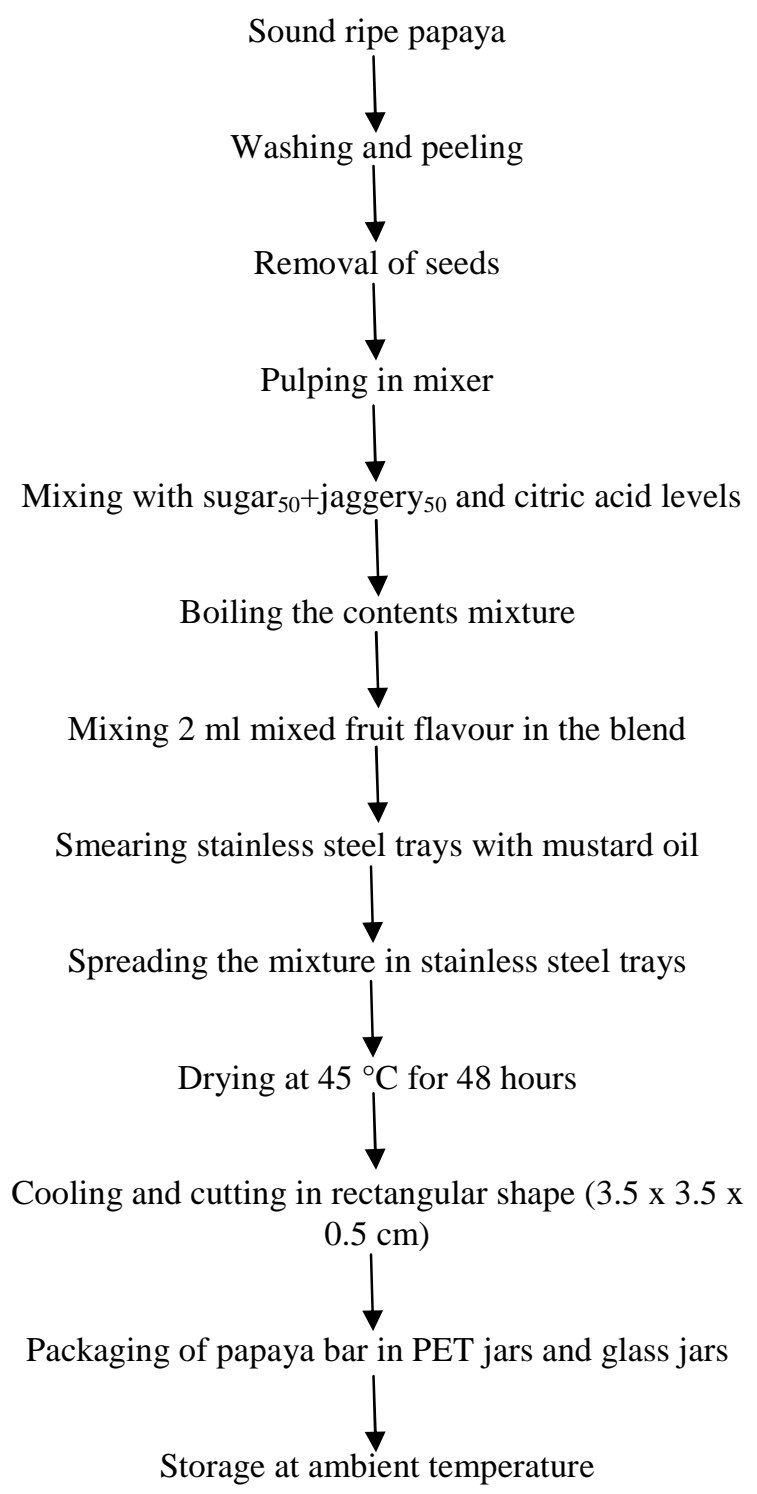

Moisture content $\%=\frac{\text { Loss in weight of sample }}{\text { Initial weight of sample }}$

Total soluble solids ( TSS $^{\circ}$ Brix): Total soluble solids value is defined as the percentage concentration amount of sugar and soluble minerals present in any food or substances. TSS $\left({ }^{\circ}\right.$ Brix) of papaya bar was measured by Hand Refractometer of range of $62-98^{\circ}$ Brix, which is based on the principal of the total refraction. Using the method recommended by (Srivastava and Kumar, 1994). A drop of sample was placed on the prism and the observation was taken in front of sunlight. The visible scale showed a dark line indication measuring TSS in degree "Brix".

pH measurement: $10 \mathrm{~g}$ of developed fruit bar were taken along with $50 \mathrm{ml}$ distilled water homogenized in a mixer grinder. The ground sample was filtered and the $\mathrm{pH}$ was determined by dipping the combined glass electrode of a digital $\mathrm{pH}$ meter (Elico, LI-127, Indian Make) into the filtrate.

Optical density (enzymatic browning): Optical density was determined using the method as recommended by (Srivastava and Kumar, 1994). 5 gm. of sample taken and mixed well in $100 \mathrm{ml}$ of $60 \%$ alcohol. Kept for 12 hours in a refrigerator and filtered using No. 1 whattman filter paper. The instrument, Digital Spectrophotometer (Elico, SLI -71 Model) was calibration knob for O.D. to 0 value at $440 \mathrm{~nm}$ wavelength. Filtrate was then inserted similarly and reading was recorded. Browning index was expressed in terms of optical density (O.D.).

Mathematically, O.D. of the medium is given by formula,

$$
\text { Optical Density }=\log \mathrm{I}_{0}
$$

Where,

$$
\begin{aligned}
& \mathrm{I}_{0}=\text { Intensity of the incident light } \\
& \mathrm{I}_{\mathrm{t}}=\text { Intensity of light transmitted through the } \\
& \text { medium. }
\end{aligned}
$$

Ascorbic acid percentage: Take sample and dissolve and after that weighing the $10 \mathrm{~g}$ of powder blend with $3 \%$ HPO3 and make up $100 \mathrm{ml}$ with HPO3 filter end point to pink color. The formula used is given below:

Microbiological analysis

Vitamin $\mathrm{C} \%=\frac{\text { Titrate value } \times \text { dye factor } \mathrm{X} \text { volume made up }}{\text { Adequate of eatract taken } \mathrm{x} \text { welght of wolume }} \times 100$

Total plate counts: Briefly, $10 \mathrm{~g}$ fruit bar sample was homogenized in $90 \mathrm{ml}$ of normal saline solution (NSS) and serial diluted up to $10-6$ dilution and $0.1 \mathrm{ml}$ sample of each dilution was spread on selective media plates under aseptic conditions. Nutrient agar media was used to determine total plate count. After that inoculated plates were incubated at $37^{\circ} \mathrm{C}$ for $24-48 \mathrm{~h}$. The bacterial and fungal counts were determined and presented as described by APHA (1995) as cfu/gm.

Sensory quality: Sensory attributes viz. colour, 
Table 1. Changes in moisture content of papaya bar during storage as affected by levels of citric acid and packaging materials.

\begin{tabular}{|c|c|c|c|c|c|c|}
\hline \multirow{3}{*}{$\begin{array}{c}\text { Storage } \\
\text { period } \\
\text { (days) }\end{array}$} & \multicolumn{6}{|c|}{ Moisture content $(\%)$} \\
\hline & \multicolumn{2}{|c|}{$\mathbf{P S}_{50}+\mathbf{J}_{50} \mathbf{C}_{0.5}$} & \multicolumn{2}{|l|}{$\mathbf{P S}_{50}+\mathbf{J}_{50} \mathbf{C}_{0.75}$} & \multicolumn{2}{|l|}{$\mathbf{P S}_{50}+\mathbf{J}_{50} \mathrm{C}_{1.0}$} \\
\hline & Pet jar & Glass jar & $\overline{\text { Pet jar }}$ & Glass jar & Pet jar & Glass jar \\
\hline Fresh & $19.00 \pm 0.017$ & $19.00 \pm 0.006$ & $19.06 \pm 0.012$ & $19.06 \pm 0.014$ & $19.11 \pm 0.020$ & $19.11 \pm 0.008$ \\
\hline 15 & $18.19 \pm 0.020$ & $18.78 \pm 0.012$ & $18.25 \pm 0.016$ & $18.80 \pm 0.037$ & $18.26 \pm 0.034$ & $18.93 \pm 0.024$ \\
\hline 30 & $18.06 \pm 0.012$ & $18.60 \pm 0.016$ & $18.10 \pm 0.024$ & $18.62 \pm 0.020$ & $18.17 \pm 0.017$ & $18.65 \pm 0.028$ \\
\hline 45 & $17.74 \pm 0.021$ & $17.82 \pm 0.024$ & $17.89 \pm 0.024$ & $17.98 \pm 0.012$ & $17.83 \pm 0.014$ & $18.02 \pm 0.016$ \\
\hline 60 & $17.37 \pm 0.012$ & $17.42 \pm 0.012$ & $17.41 \pm 0.016$ & $17.86 \pm 0.020$ & $17.49 \pm 0.016$ & $17.91 \pm 0.024$ \\
\hline 75 & $17.29 \pm 0.030$ & $17.34 \pm 0.012$ & $17.37 \pm 0.032$ & $17.52 \pm 0.020$ & $17.39 \pm 0.009$ & $17.58 \pm 0.023$ \\
\hline 90 & $16.89 \pm 0.047$ & $16.98 \pm 0.023$ & $16.95 \pm 0.012$ & $17.06 \pm 0.017$ & $16.99 \pm 0.029$ & $17.11 \pm 0.014$ \\
\hline
\end{tabular}

Mean values are 4 replicates, $\mathrm{PS}_{50}+\mathrm{J}_{50} \mathrm{C}_{0.5}=$ Papaya sugar $50 \%+$ jaggery $50 \%$, citric acid level $0.5 \%, \mathrm{PS}_{50}+\mathrm{J}_{50} \mathrm{C}_{0.75}=$ Papaya sugar $50 \%$ + jaggery $50 \%$, citric acid level $0.75 \%, \mathrm{PS}_{50}+\mathrm{J}_{50} \mathrm{C}_{1.0}=$ Papaya sugar $50 \%$ + jaggery $50 \%$, citric acid level $1.0 \%$

Table 2. Changes in total soluble solids content of papaya bar during storage as affected by levels of citric acid and packaging materials.

\begin{tabular}{cllllll}
\hline \multirow{2}{*}{$\begin{array}{c}\text { Storage } \\
\text { period } \\
\text { (days) }\end{array}$} & \multicolumn{5}{c}{ Total soluble solids (TSS ${ }^{\circ} \mathbf{B R I X )}$} \\
\cline { 2 - 7 } & $\mathbf{P S}_{\mathbf{5 0}}+\mathbf{J}_{\mathbf{5 0}} \mathbf{C}_{\mathbf{0 . 5}}$ & Pet jar & Glass jar & Pet jar & Glass jar & $\mathbf{P S}_{\mathbf{5 0}}+\mathbf{J}_{\mathbf{5 0}} \mathbf{C}_{\mathbf{0 . 7 5}} \mathbf{J}_{\mathbf{5} \mathbf{0}} \mathbf{C}_{\mathbf{1 . 0}}$ \\
\hline Fresh & $64.26 \pm 0.020$ & $64.26 \pm 0.011$ & $64.17 \pm 0.012$ & $64.17 \pm 0.037$ & $64.06 \pm 0.042$ & $64.06 \pm 0.029$ \\
15 & $64.58 \pm 0.074$ & $64.64 \pm 0.053$ & $64.40 \pm 0.017$ & $64.48 \pm 0.024$ & $64.31 \pm 0.075$ & $64.40 \pm 0.016$ \\
30 & $65.33 \pm 0.037$ & $65.31 \pm 0.024$ & $65.23 \pm 0.016$ & $65.37 \pm 0.027$ & $65.15 \pm 0.012$ & $65.21 \pm 0.020$ \\
45 & $66.36 \pm 0.013$ & $66.47 \pm 0.018$ & $66.24 \pm 0.017$ & $66.39 \pm 0.017$ & $66.16 \pm 0.016$ & $66.31 \pm 0.032$ \\
60 & $67.38 \pm 0.016$ & $67.51 \pm 0.017$ & $67.25 \pm 0.018$ & $67.41 \pm 0.029$ & $67.17 \pm 0.013$ & $67.33 \pm 0.016$ \\
75 & $68.35 \pm 0.029$ & $68.50 \pm 0.012$ & $68.27 \pm 0.017$ & $68.39 \pm 0.021$ & $68.09 \pm 0.016$ & $68.20 \pm 0.024$ \\
90 & $69.40 \pm 0.024$ & $69.55 \pm 0.013$ & $69.30 \pm 0.025$ & $69.46 \pm 0.028$ & $69.20 \pm 0.020$ & $69.38 \pm 0.032$ \\
\hline
\end{tabular}

Mean values are 4 replicates

Table 3. Changes in $\mathrm{pH}$ content of papaya bar during storage as affected by levels of citric acid and packaging materials.

\begin{tabular}{|c|c|c|c|c|c|c|}
\hline \multirow{3}{*}{$\begin{array}{l}\text { Storage } \\
\text { period } \\
\text { (days) }\end{array}$} & \multicolumn{6}{|c|}{ pH } \\
\hline & \multicolumn{2}{|l|}{$\mathbf{P S}_{50}+\mathbf{J}_{50} \mathbf{C}_{0.5}$} & \multicolumn{2}{|l|}{$\mathrm{PS}_{50}+\mathrm{J}_{50} \mathrm{C}_{0.75}$} & \multicolumn{2}{|l|}{$\mathbf{P S}_{50}+\mathrm{J}_{50} \mathrm{C}_{1.0}$} \\
\hline & Pet jar & Glass jar & Pet jar & Glass jar & Pet jar & Glass jar \\
\hline Fresh & $3.71 \pm 0.052$ & $3.71 \pm 0.032$ & $3.63 \pm 0.004$ & $3.63 \pm 0.024$ & $3.61 \pm 0.008$ & $3.61 \pm 0.021$ \\
\hline 15 & $3.64 \pm 0.024$ & $3.64 \pm 0.012$ & $3.62 \pm 0.008$ & $3.61 \pm 0.016$ & $3.59 \pm 0.016$ & $3.59 \pm 0.012$ \\
\hline 30 & $3.65 \pm 0.028$ & $3.64 \pm 0.020$ & $3.62 \pm 0.020$ & $3.61 \pm 0.008$ & $3.59 \pm 0.016$ & $3.58 \pm 0.013$ \\
\hline 45 & $3.64 \pm 0.021$ & $3.62 \pm 0.016$ & $3.61 \pm 0.016$ & $3.61 \pm 0.008$ & $3.59 \pm 0.029$ & $3.58 \pm 0.004$ \\
\hline 60 & $3.62 \pm 0.013$ & $3.60 \pm 0.028$ & $3.60 \pm 0.021$ & $3.59 \pm 0.032$ & $3.57 \pm 0.012$ & $3.57 \pm 0.036$ \\
\hline 75 & $3.61 \pm 0.012$ & $3.61 \pm 0.014$ & $3.57 \pm 0.025$ & $3.57 \pm 0.012$ & $3.57 \pm 0.016$ & $3.56 \pm 0.026$ \\
\hline 90 & $3.59 \pm 0.032$ & $3.57 \pm 0.020$ & $3.58 \pm 0.028$ & $3.55 \pm 0.024$ & $3.56 \pm 0.021$ & $3.53 \pm 0.028$ \\
\hline
\end{tabular}

Mean values are 4 replicates

Table 4. Changes in optical density content of papaya bar during storage as affected by levels of citric acid and packaging materials.

\begin{tabular}{|c|c|c|c|c|c|c|}
\hline \multirow{3}{*}{$\begin{array}{c}\text { Storage } \\
\text { period } \\
\text { (days) }\end{array}$} & \multicolumn{6}{|c|}{ Optical density } \\
\hline & \multicolumn{2}{|l|}{$\mathbf{P S}_{50}+\mathbf{J}_{50} \mathbf{C}_{0.5}$} & \multicolumn{2}{|l|}{$\mathrm{PS}_{50}+\mathrm{J50C}_{0.75}$} & \multicolumn{2}{|l|}{$\mathbf{P S}_{50}+\mathbf{J}_{50} \mathbf{C}_{1.0}$} \\
\hline & Pet jar & Glass jar & Pet jar & Glass jar & Pet jar & Glass jar \\
\hline Fresh & $0.055 \pm 0.006$ & $0.055 \pm 0.017$ & $0.052 \pm 0.014$ & $0.052 \pm 0.012$ & $0.051 \pm 0.008$ & $0.051 \pm 0.020$ \\
\hline 15 & $0.056 \pm 0.008$ & $0.057 \pm 0.009$ & $0.053 \pm 0.004$ & $0.054 \pm 0.012$ & $0.051 \pm 0.012$ & $0.053 \pm 0.016$ \\
\hline 30 & $0.059 \pm 0.012$ & $0.060 \pm 0.028$ & $0.056 \pm 0.020$ & $0.057 \pm 0.030$ & $0.053 \pm 0.025$ & $0.055 \pm 0.018$ \\
\hline 45 & $0.061 \pm 0.016$ & $0.063 \pm 0.024$ & $0.058 \pm 0.002$ & $0.060 \pm 0.031$ & $0.056 \pm 0.029$ & $0.058 \pm 0.028$ \\
\hline 60 & $0.064 \pm 0.036$ & $0.066 \pm 0.017$ & $0.061 \pm 0.029$ & $0.063 \pm 0.008$ & $0.059 \pm 0.024$ & $0.061 \pm 0.012$ \\
\hline 75 & $0.067 \pm 0.024$ & $0.069 \pm 0.017$ & $0.064 \pm 0.019$ & $0.065 \pm 0.012$ & $0.062 \pm 0.008$ & $0.064 \pm 0.028$ \\
\hline 90 & $0.069 \pm 0.021$ & $0.071 \pm 0.028$ & $0.067 \pm 0.016$ & $0.068 \pm 0.023$ & $0.064 \pm 0.011$ & $0.066 \pm 0.015$ \\
\hline
\end{tabular}

Mean values are 4 replicates

flavour, taste, texture, tooth packing and overall acceptability of the samples were evaluated. Hedonic rating test as recommended by (Ranganna, 1994) was used for the purpose of evaluation. This test measures the consumer's acceptability. Detailed methodology is explained below:
A semi trained panel consisting of more than 10 members of different age groups having different eating habits was selected to evaluate the sensory quality. The judgments were quantified by appropriate analysis for determining the overall quality. Samples were served to the panelists and they were asked to 
Table 5. Changes in Ascorbic acid content of papaya bar during storage as affected by levels of citric acid and packaging materials.

\begin{tabular}{|c|c|c|c|c|c|c|}
\hline \multirow{3}{*}{$\begin{array}{c}\text { Storage } \\
\text { Period } \\
\text { (days) }\end{array}$} & \multicolumn{6}{|c|}{ Ascorbic acid } \\
\hline & \multicolumn{2}{|l|}{$\mathbf{P S}_{50}+\mathbf{J}_{50} \mathbf{C}_{0.5}$} & \multicolumn{2}{|l|}{$\mathrm{PS}_{50}+\mathrm{J}_{50} \mathrm{C}_{0.75}$} & \multicolumn{2}{|l|}{$\mathbf{P S}_{\mathbf{5 0}}+\mathrm{J}_{50} \mathbf{C}_{1.0}$} \\
\hline & Pet jar & Glass jar & Pet jar & Glass jar & Pet jar & Glass jar \\
\hline Fresh & $56.40 \pm 0.024$ & $56.40 \pm 0.024$ & $55.30 \pm 0.012$ & $55.30 \pm 0.028$ & $54.10 \pm 0.016$ & $54.10 \pm 0.028$ \\
\hline 15 & $55.05 \pm 0.019$ & $55.20 \pm 0.018$ & $54.00 \pm 0.030$ & $54.05 \pm 0.012$ & $53.00 \pm 0.024$ & $53.85 \pm 0.016$ \\
\hline 30 & $54.00 \pm 0.036$ & $54.05 \pm 0.028$ & $52.85 \pm 0.042$ & $52.90 \pm 0.019$ & $52.05 \pm 0.034$ & $52.60 \pm 0.029$ \\
\hline 45 & $52.55 \pm 0.040$ & $52.85 \pm 0.018$ & $51.65 \pm 0.018$ & $51.95 \pm 0.013$ & $50.95 \pm 0.042$ & $51.45 \pm 0.032$ \\
\hline 60 & $50.85 \pm 0.028$ & $51.80 \pm 0.024$ & $50.40 \pm 0.046$ & $50.65 \pm 0.036$ & $48.70 \pm 0.028$ & $49.95 \pm 0.019$ \\
\hline 75 & $48.95 \pm 0.032$ & $50.55 \pm 0.030$ & $48.70 \pm 0.028$ & $48.80 \pm 0.036$ & $46.40 \pm 0.018$ & $46.65 \pm 0.046$ \\
\hline 90 & $46.85 \pm 0.042$ & $47.90 \pm 0.042$ & $45.80 \pm 0.034$ & $46.75 \pm 0.036$ & $44.65 \pm 0.028$ & $45.30 \pm 0.046$ \\
\hline
\end{tabular}

Mean values are 4 replicates

Table 6. Changes in total plate count $\left(\mathrm{x} 10^{3} \mathrm{CFU} / \mathrm{g}\right)$ of papaya bar during storage as affected by levels of citric acid and packaging materials.

\begin{tabular}{|c|c|c|c|c|c|c|}
\hline \multirow{3}{*}{$\begin{array}{l}\text { Storage period } \\
\text { (days) }\end{array}$} & \multicolumn{6}{|c|}{ Total Plate Count $\left(\times 10^{3} \mathrm{CFU} / \mathrm{g}\right)$} \\
\hline & \multicolumn{2}{|l|}{$\mathrm{PS}_{50}+\mathrm{J}_{50} \mathrm{C}_{0.5}$} & \multicolumn{2}{|c|}{$\mathrm{PS}_{50}+\mathrm{J}_{50} \mathrm{C}_{0.75}$} & \multicolumn{2}{|c|}{$\mathrm{PS}_{50}+\mathrm{J}_{50} \mathrm{C}_{1.0}$} \\
\hline & Pet jar & Glass jar & Pet jar & Glass jar & Pet jar & Glass jar \\
\hline Fresh & ND & ND & $\mathrm{ND}$ & ND & ND & ND \\
\hline 15 & $0.50 \pm 0.02$ & $0.49 \pm 0.07$ & ND & ND & ND & ND \\
\hline 30 & $0.95 \pm 0.12$ & $0.93 \pm 0.07$ & $0.90 \pm 0.26$ & $0.88 \pm 0.13$ & $0.68 \pm 0.26$ & $0.68 \pm 0.05$ \\
\hline 45 & $1.41 \pm 0.23$ & $1.40 \pm 0.02$ & $1.27 \pm 0.23$ & $0.26 \pm 0.13$ & $1.12 \pm 0.26$ & $1.10 \pm 0.31$ \\
\hline 60 & $2.39 \pm 0.06$ & $2.36 \pm 0.09$ & $2.09 \pm 0.09$ & $2.09 \pm 0.09$ & $1.93 \pm 0.01$ & $1.90 \pm 0.12$ \\
\hline 75 & $2.78 \pm 0.11$ & $2.76 \pm 0.10$ & $2.36 \pm 0.03$ & $2.35 \pm 0.04$ & $2.20 \pm 0.03$ & $2.16 \pm 0.07$ \\
\hline 90 & $3.17 \pm 0.14$ & $3.15 \pm 0.03$ & $3.05 \pm 0.34$ & $3.04 \pm 0.02$ & $2.85 \pm 0.15$ & $2.83 \pm 0.08$ \\
\hline
\end{tabular}

Mean values are 4 replicates

Table 7. Change in overall acceptability of papaya bar as affected by citric acid levels and packaging materials of fresh and stored papaya bar.

\begin{tabular}{|c|c|c|c|c|c|c|}
\hline \multirow{3}{*}{$\begin{array}{c}\text { Sensory } \\
\text { attributes } \\
\text { (days) }\end{array}$} & \multicolumn{6}{|c|}{ Sensory score } \\
\hline & \multicolumn{2}{|c|}{$\mathrm{PS}_{50}+\mathrm{J}_{50} \mathrm{C}_{0.5}$} & \multicolumn{2}{|c|}{$\mathbf{P S}_{50}+\mathrm{J}_{50} \mathrm{C}_{0.75}$} & \multicolumn{2}{|c|}{$\mathrm{PS}_{50}+\mathrm{J}_{50} \mathrm{C}_{1.0}$} \\
\hline & Pet jar & Glass jar & Pet jar & Glass jar & Pet jar & Glass jar \\
\hline Fresh & $7.32 \pm 0.08$ & $7.32 \pm 0.08$ & $7.457 \pm 0.130$ & $7.457 \pm 0.130$ & $7.227 \pm 0.35$ & $7.227 \pm 0.35$ \\
\hline 30 days & $7.27 \pm 0.016$ & $7.295 \pm 0.022$ & $7.40 \pm 0.028$ & $7.447 \pm 0.042$ & $7.185 \pm 0.044$ & $7.205 \pm 0.024$ \\
\hline 60 days & $7.237 \pm 0.032$ & $7.227 \pm 0.036$ & $7.365 \pm 0.014$ & $7.43 \pm 0.018$ & $7.155 \pm 0.020$ & $7.18 \pm 0.024$ \\
\hline 90 days & $7.157 \pm 0.016$ & $7.247 \pm 0.028$ & $7.325 \pm 0.044$ & $7.375 \pm 0.014$ & $7.127 \pm 0.025$ & $7.142 \pm 0.012$ \\
\hline
\end{tabular}

Mean values are 4 replicates

rate the acceptability of the product through sense of organs. Different attributes viz. colour, flavour, taste, texture, and overall acceptability were rated on the basis of 9-point hedonic scale ranging from 1 (dislike extremely/most undesirable) to 9 (like extremely/most desirable). A test performa was also prepared and supplied to them at the time of evaluation.

Statistical analysis: The best and most commonly used statistical evaluation of the precision of analytical data is the standard deviation. The standard deviation measures the spread of the experimental values and gives a good indication of how close the values are to each other. Samples were prepared in three replication and data obtained for selected quality parameters were analyzed.

\section{RESULTS AND DISCUSSION}

\section{Physicochemical properties of papaya bar}

Moisture content of fruit bar: The details of moisture content of developed fruit bars were presented in Table 1 . Moisture content of samples increased with increase in citric acid levels and decreased with storage period. The reason for such trend may attributed to inversion of sucrose into monosaccharide by citric acid which is more in hygroscopic nature than the sucrose (Bhandari et al., 1997), (Bhandari Howes, 1999) leading to relatively higher affinity for water molecules. Samples with higher level of citric acid were undergone inversion of more sucrose and therefore, had higher final moisture content. It was evident that the moisture decreased less in glass jars as compared to the PET jars.

TSS of fruit bar: TSS (total soluble solids) of bar samples decreased with increased in the levels of citric acid but the TSS of all bar samples prepared with different levels of citric acid increased with storage period. It was also shown that the TSS of samples packed in glass jars was higher as compared to the PET jars after storage of 90 days. TSS was found to be higher for samples prepared by sugar $_{50}+$ jaggery $_{50}$ at 0.5 percent citric acid level than those of sugar $_{50}+$ jaggery $_{50}$ at 0.75 percent and sugar ${ }_{50}+$ jaggery $_{50}$ at 1.0 percent citric acid level. But it was also shown that in case of samples with different level of citric acids, TSS was found to be increase on 90 days of storage period (Table 2). Increasing trends in TSS content during storage cor- 
roborates with findings of earlier researchers (Jain et al., 2011) in the study of quality of guava and papaya fruit pulp as influenced by blending ratio and storage period.

pH of fruit bar: $\mathrm{pH}$ of the bar samples decreased with increased in the levels of citric acid. From the Table 3 it is also observed that the $\mathrm{pH}$ of the samples prepared with different levels of citric acid decreased during storage. Similar pattern of decreasing trend was reported by (Sivakumar et al. 2005) as the decreases in $\mathrm{pH}$ was due to increase in acidity. Among the packaging materials, the bar samples stored in PET jars had recorded higher $\mathrm{pH}$ followed by glass jars.

Optical density of fruit bar: Optical density of the bar samples decreased with increased in the levels of citric acid. From the table 4 it is evident that the optical density of the samples prepared with different levels of citric acid increased during storage. Non-enzymatic maillard browning reaction may take place between nitrogenous compounds and sugar, nitrogenous compound and organic acids and among organic acids themselves (Srivastava and Kumar, 2000).

Ascorbic acid (mg per 100g) of fruit bar: Ascorbic acid of the bar samples decreased with increased in the levels of citric acid. From the table 5 it is also showed that the Vitamin-C content of the samples prepared with different levels of citric acid decreased after 90 days of storage. The reason behind this is the ascorbic acid content decreased during storage due to oxidation of ascorbic acid to dehyroascorbic acid. Decreasing trend in ascorbic acid content during storage corroborates with findings of earlier researchers (Pareek and Kaushik, 2012) in the study of effect of drying methods of quality of Indian gooseberry powder during storage. The loss of Vitamin-C was more in samples packed in PET jars as compared to glass jars.

\section{Microbiological analysis of fruit bar}

Total plate counts of fruit bar: The details of microbial quality of developed fruit bars were presented in Table 6. It was observed that microbial growth was decreased with increase in the levels of citric acid but total plate count of all bar samples prepared with different levels of citric acid increased with storage period. It is also observed that samples packed in PET jars had more total plate count as compared to glass jars after storage of 90 days. The growth of microorganism could cause spoiling of fruits bar, however less numbers of microorganisms present initially, resulted in more shelf life in the developed fruits bar.

Sensory quality of fruit bar: Table 7 shows the oragnoleptic score values for bar samples during storage. Results of sensory evaluation showed that the sensory attributes like colour, flavour, texture and taste of samples prepared with different levels of citric acid in glass jars were most acceptable upto 90 days of storage at room temperature. The results also indicated that samples prepared with citric acid level of $0.75 \%$ ranked higher followed by $0.5 \%$ and $1.0 \%$ citric acid levels.

\section{Conclusion}

It was concluded that sugar $_{50}+$ jaggery $_{50}$ at 0.75 percent citric acid level gave better products after 90 days of storage followed by sugar $_{50}+$ jaggery $_{50}$ at 0.5 percent citric acid level and sugar ${ }_{50}+$ jaggery $_{50}$ at 1.0 percent citric acid level. The glass was found suitable packaging material for storage for papaya leather. Significant changes were noticed in moisture content $(19.06 \%$ to $17.06 \%$ ), TSS (64.17 to $\left.69.46^{\circ} \mathrm{Brix}\right)$, ph (3.63 to 3.55$)$, optical density (0.052 to 0.068$)$, Vitamin-C (55.30 to $46.75 \mathrm{mg} / 100 \mathrm{mg}$ ). The result indicated that the samples prepared with citric acid level of $0.75 \%$ ranked high followed by $0.5 \%$ and $1.0 \%$ citric acid levels.

\section{REFERENCES}

APHA (1995). Standard Methods for the Examination of Water and Wastewater (19th Ed.). APHA, Washington, DC, USA.

Bhandari, B.R. and Howes, T. (1999). Implementation of glass transition for the drying and stability of dried foods. $J$. Food Engg., 40: 71-79.

Bhandari, B. R., Datta, N., Howes, T. (1997). Problem associated with spray drying of sugar rich foods. Drying Technol, 12 (2): 671-684.

Doreyappa, G.I.N., Amba, D. and Ramanjaneya, K.H. (1995). Studies on mango fruit bar preparation. Ind. $F d$. Packer, 49 (2): 17-24.

Jain K.P., Jain P. And Nema, K.P. (2011). Quality of guava and papaya fruit pulp as influenced by blending ratio and storage period. American Journal of Food Technology, 6 (6): 507-512.

Mathur, N.K., Anthony, D.S., Jayaraman, K.S. and Bhatia, B. S. (1972). Preparation of fruit bars used in combat rations, Ind. Fd. Packer, March-April, 33-35.

Pareek S. and Kaushik, A.R. (2012). Effect of drying methods of quality of Indian gooseberry (Emblica officinalis Gaertn.) powder during storage. Journal of Scientific and Industrial Research, 71 : 727-732.

Ram, B. (1982). Studies on processing and preservation of aonla fruit beverages. M.Sc. Thesis, N.D.U.A. \& T, Kumarganj, Faizabad.

Ranganna, S. (1994). Hand book of analysis and quality control of fruit and vegetable products. Published by Tata McGraw Hill Publishing Company Limited, New Delhi.

Singh and Sirohi (1977). Timing of the ethephon application ripening and quality of rasin grape c.v. Block Corianth Haryana Agri. University, J. Res., 7 : 97.

Sivakumar, P.K., Malathi, D., Nallakurumban, B. and Kalaiselvan, A. (2005). Studies on storage stability of guava bar in different packaging materials. Beverage and Food World, Nov. $80-81$.

Srivastava, R.P. and Kumar, S. (1994). Fruits and vegetables preservation (principles and facts). International Book Distributing Company, Charbagh, Lucknow, 1994.

Srivastava, R.P. and Kumar, S. (2000). Fruit and vegetables preservation (Principal and Facts). International Book Distributing Company, Charbag, Lucknow, 1994.

Vatthanakul S., Jangchud A., Jangchud K., Therdthai N. and Wilkinson B. (2010). Gold kiwifruit leather product development using quality function deployment approach, Food Quality and Preference, 21 (3): 339-345. 